Article

\title{
Investigation of Heterologously Expressed Glucose-6-Phosphate Dehydrogenase Genes in a Yeast zwf1 Deletion
}

\author{
Jürgen J. Heinisch ${ }^{1, *}$, Johannes Knuesting ${ }^{2}$ and Renate Scheibe ${ }^{2, *(1)}$ \\ 1 Fachbereich Biologie/Chemie, Universität Osnabrück, AG Genetik, Barbarastr. 11, \\ D-49076 Osnabrück, Germany \\ 2 Fachbereich Biologie/Chemie, Universität Osnabrück, AG Pflanzenphysiologie, Barbarastr. 11, \\ D-49076 Osnabrück, Germany; knuesting@gmail.com \\ * Correspondence: jheinisc@uos.de (J.J.H.); rscheibe@uni-osnabrueck.de (R.S.); Tel.: +49-541-969-2290 (J.J.H.)
}

Received: 5 March 2020; Accepted: 8 April 2020; Published: 9 April 2020

\begin{abstract}
Glucose-6-phosphate dehydrogenase (G6PD) is a key enzyme of the oxidative part of the pentose phosphate pathway and serves as the major source of NADPH for metabolic reactions and oxidative stress response in pro- and eukaryotic cells. We here report on a strain of the model yeast Saccharomyces cerevisiae which lacks the G6PD-encoding ZWF1 gene and displays distinct growth retardation on rich and synthetic media, as well as a strongly reduced chronological lifespan. This strain was used as a recipient to introduce plasmid-encoded heterologous G6PD genes, synthesized in the yeast codon usage and expressed under the control of the native PFK2 promotor. Complementation of the hypersensitivity of the zwf1 mutant towards hydrogen peroxide to different degrees was observed for the genes from humans (HsG6PD1), the milk yeast Kluyveromyces lactis (KIZWF1), the bacteria Escherichia coli (EcZWF1) and Leuconostoc mesenteroides (LmZWF1), as well as the genes encoding three different plant G6PD isoforms from Arabidopsis thaliana (AtG6PD1, AtG6PD5, AtG6PD6). The plastidic AtG6PD1 isoform retained its redox-sensitive activity when produced in the yeast as a cytosolic enzyme, demonstrating the suitability of this host for determination of its physiological properties. Mutations precluding the formation of a disulfide bridge in AtG6PD1 abolished its redox-sensitivity but improved its capacity to complement the yeast zwf 1 deletion. Given the importance of G6PD in human diseases and plant growth, this heterologous expression system offers a broad range of applications.
\end{abstract}

Keywords: Baker's yeast; pentose phosphate pathway; oxidative stress; heterologous expression

\section{Introduction}

All cells from bacteria to humans have developed mechanisms to cope with oxidative stress caused by reactive oxygen species (ROS), which are a by-product of respiratory metabolism and cause damage to membranes and DNA [1]. The importance of corresponding signaling pathways that elicit a proper cellular response to ROS accumulation, especially in tumor cells, has been underlined by studies ultimately earning last year's award of the Nobel prize for physiology and medicine (see [2], and references therein). Glucose-6-phosphate dehydrogenase (G6PD), a key enzyme of the pentose phosphate pathway (PPP) generates NADPH required to detoxify ROS, but also for methionine biosynthesis $[3,4])$. In human erythrocytes, G6PD is the exclusive source of NADPH and related to the most common human enzymopathic condition [5,6]. G6PD also plays a pivotal role in cancer cell proliferation, cellular signaling, embryogenesis, apoptosis, neurodegeneration [7-9], and cardiac dysfunction in mouse models [10]. The human G6PD gene resides on the X-chromosome and 
heterozygosity for some mutations may protect against malaria infections [11]. This correlates with the observation that the malaria parasite, Plasmodium falciparum, is very sensitive to oxidative stress, and drugs targeted towards its native G6PD are used to combat infections [12].

The model plant Arabidopsis thaliana has six isoforms of G6PD (AtG6PD1-6), of which the first four are localized in the plastids, whereas the isoforms 5 and 6 reside in the cytosol [13]. In a more recent study, it was shown that G6PD4 is in fact encoding a non-functional isoform, belonging to a new group, namely P0, that is activated under stress, forming double heterodimers with G6PD1, and is translocated to peroxisomes [14]. While the cytosolic forms are insensitive to modulations by the cells' redox state [15], the plastidial isozymes G6PD1-3 undergo light-dark-modulation and are only active in their oxidized state. Such thiol-disulfide exchange reaction allows for the formation of a reversible disulfide bridge between two regulatory cysteine residues located in a unique loop [16,17]. The reduced form occurs primarily in the illuminated chloroplast where photosynthetic electron flow from reduced ferredoxin, mediated by the ferredoxin-thioredoxin reductase reduces thioredoxin (Trx m). In the light phase, it is largely inactive due to its low substrate affinity [18]. This redox-switch functions due to continuous reoxidation in the light, and rapid oxidation when the electron flow stops upon darkening [19]. The affinity of the oxidized enzyme towards glucose 6-phosphate (G6P) is largely increased [20], so that the enzyme is fully active under physiological G6P concentrations [21]. As a consequence, light-inactivation of the plastidial oxidative PPP prevents futile cycling when the Calvin-Benson cycle enzymes of the reductive PPP are activated for assimilate $\mathrm{CO}_{2}$ during the day, thus precluding simultaneous glucose oxidation [19]. However, the physiological characterization of a single G6PD isozyme in the native plant is hampered by the overlapping activities of the six isozymes. The reductive power generated by G6PD is of central importance to plants, since it ensures survival under conditions of salt, drought, and other types of oxidative stress [22-24]. Accordingly, transgenic plants with increased levels of G6PD in plastids, or isoform replacement by cytosolic expression of the gene encoding the plastidic isoform P2 in tobacco, which is insensitive to feedback-inhibition by NADPH, were more resistant towards oxidative stress $[25,26]$. Moreover, the increased reducing power required during nitrate assimilation is also met by elevating the activity of the oxidative part of the PPP in plastids $[27,28]$.

In the Baker's yeast Saccharomyces cerevisiae, mutants in the single gene encoding G6PD (ZWF1 for "Zwischenferment", derived from early studies of the PPP) were first reported by [29]. The gene was cloned and sequenced in the early 1990s and employed to construct deletion mutants [30,31]. These mutants were hyper-sensitive towards oxidative stress, such as the addition of hydrogen peroxide, diamide and phenylhydrazine, and are auxotrophic for methionine, underlining the predominant role of G6PD in the production of cytosolic NADPH, since besides its role for glutathione reduction to scavenge ROS, three molecules of NADPH are required for the synthesis of one molecule of methionine [4]. The PPP has been suggested to provide the fastest response of S. cerevisiae towards oxidative stress, exerted within seconds after its application [32]. This involves a complex interplay between glycolysis and the PPP, which are linked via the production of fructose-6-phosphate and glyceraldehyde3-phosphate by the transaldolase and transketolase reactions within the non-oxidative part of the PPP [33]. Yet, the contribution of the PPP to energy production differs significantly between different yeasts. While under standard growth conditions, less than $5 \%$ of the glucose is channeled into the oxidative PPP in S. cerevisiae [34], mutant studies in the milk yeast Kluyveromyces lactis indicate that the PPP and glycolysis are equally important for its metabolism $[35,36]$.

Oxidative stress triggers a fast inactivation of glyceraldehyde-3-phosphate dehydrogenase (GAPDH) and triosephosphate isomerase (TIM) in the glycolytic pathway, concomitant with activation of NADPH production by Zwf1, as observed both in S. cerevisiae and in Caenorhabditis elegans [37]. According to an initial hypothesis, the flux through Zwf1 would be due to the accumulation of upstream glycolytic metabolites. However, based on metabolome analyses performed with human cells, it is now believed that the inhibition of glycolysis at the triosephosphate level merely provides a means of recycling of glucose-6-phosphate as a substrate for G6PD [38,39]. In this scenario, inhibition of G6PD 
by NADPH and ATP, which reduces the efficiency of the G6PD reaction to less than 1\% of its maximal capacity in human erythrocytes [40], would be alleviated by the reduced concentration of NADPH as it is channeled towards the reduction of glutathione and the scavenging of ROS [38]. Within this regulatory system, glycolytic GAPDH appears to be most sensitive towards oxidation at its catalytic cysteine residue, thus creating a highly responsive thiol-switch to reroute metabolism as an additional function $[41,42]$.

We here expressed G6PD genes from several organisms in a zwf1 deletion strain of S. cerevisiae. Besides the opportunity to study the biochemical properties of the encoded enzyme in the context of a heterologous expression system, this provides the basis for the screening of genes for special purposes to be used in synthetic biology and biotechnology. Moreover, it will allow high-throughput screens for the discovery of drugs targeting G6PD. Importantly, in the genetic background of the strain used herein, a zwf1 deletion impairs vegetative growth under standard growth conditions, increases the sensitivity towards oxidative stress, and affects chronological lifespan.

\section{Materials and Methods}

\subsection{Strains, Media, and Culture Conditions}

For construction of deletions in S. cerevisiae, the diploid strain DHD5 (MATa/MAT $\alpha$ ura3-52/ura3-52 leu2-3,112/leu2-3,112 his3-11,15/his3-11,15; [43]) was employed and haploid segregants were obtained from tetrad analyses. The parental haploid strain HD56-5A (MAT $\alpha$ ura3-52 leu2-3,112 his3-11,15; [44]) served as a wild-type control in different experiments, and is actually one of the parental strains of the commonly employed CEN.PK series [45].

Rich media were based on yeast extract $(1 \% \mathrm{w} / \mathrm{v})$, peptone $(2 \% \mathrm{w} / \mathrm{v})$ from Difco Laboratories Inc., Detroit, MI, USA, with glucose ( $2 \% \mathrm{w} / \mathrm{v})$ as a carbon source (YEPD). Synthetic media were prepared with Difco yeast nitrogen base with ammonium sulfate as described in [46], with the addition of amino acids and bases using a mixture provided by MP Biomedicals (Eschwege, Germany; CSM-His-Leu-Trp-Ura) supplemented as required for selection of plasmids or deletion markers, and $2 \%$ glucose $(\mathrm{w} / \mathrm{v})$ as a carbon source (SCD). A quantity of $200 \mathrm{mg} / \mathrm{L}$ of G418 was used for selection of the kanMX marker. Hydrogen peroxide was added at the concentrations indicated to induce oxidative stress. For the preparation of solid media, $1.5 \%$ agar was added prior to sterilization. Hydrogen peroxide was added to provoke oxidative stress at a concentration of $1.75 \mathrm{mM}$. Yeasts were incubated at $30{ }^{\circ} \mathrm{C}$, with constant agitation at $180 \mathrm{rpm}$ for liquid cultures. Tetrad analyses were performed on YEPD plates using zymolyase 20T for digestion of the ascus walls and a Singer Instruments micromanipulator as described in [47]. Plates were incubated for 3 days at $30^{\circ} \mathrm{C}$ and colony formation was documented by scanning. Brightness and contrast were adjusted for entire plates using Corel Photo Paint, prior to selection of exemplary four tetrads, each. A minimum of 18 tetrads were examined for each cross.

For work with E. coli, strain DH5 $\alpha$ (Invitrogen, Karlsruhe, Germany) was employed, grown at $37^{\circ} \mathrm{C}$ in LB medium $(0.5 \%$ yeast extract, $1 \%$ Bacto peptone, $0.5 \%$ sodium chloride), supplemented with ampicillin $(50 \mathrm{mg} / \mathrm{L})$ for plasmid selection.

\subsection{Serial Drop Dilution Assays}

To examine phenotypes of yeast strains in serial drop dilution assays, cells were grown overnight in selective medium. The cultures were diluted to an $\mathrm{OD}_{600}$ of 0.25 and again grown for 3-5 h. Exponentially growing cells were adjusted to an $\mathrm{OD}_{600}$ of 0.1 with fresh medium and dilutions from $10^{0}$ to $10^{-3}$ were prepared. A quantity of $3 \mu \mathrm{L}$ of each dilution was spotted onto plates with the indicated compositions and incubated for $2-3$ days at $30^{\circ} \mathrm{C}$. Growth was documented by scanning the plates, adjustment of brightness and contrast of the entire images, and trimming using Corel Photo Paint. 


\subsection{Construction of Deletion Mutants, Cloning, and Tagging of Genes}

A zwf1 deletion in S. cerevisiae was obtained by one-step gene replacement [48] by directly introducing a PCR product obtained with the primer pair 16.235/16.236 (Table 1) and pUG6-hh ${ }^{-}$ (a derivative of pUG6 described in [49], in which the two HindIII sites were eliminated each by single nucleotide exchanges) as a template into the diploid strain DHD5, selecting for G418 resistance. The correct substitution of one of the ZWF1 alleles in the heterozygous diploid was verified by PCR with the flanking oligonucleotides 16.232/16.233 (Table 1), and the respective transformant was sporulated. The haploid segregant HOD269-1C (MATa ura3-52 leu2-3,112 his3-11,15 zwf1::kanMX) was obtained from a standard tetrad analysis performed on a YEPD plate [50]. Likewise, a rpe1 deletion, supposed to be synthetically lethal with a zwf1 defect, was constructed by PCR-mediated homologous recombination, using pJJH1287 as a template for amplification of the KlLEU2 marker with the oligonucleotide pair 19.139/19.140 (Table 1). pJJH1287 is a derivative of pUG6 mentioned above, in which the KILEU2 open reading frame was placed between the TEF2 promoter and terminator sequences, substituting the kanMX resistance marker. Transformants were selected for growth on synthetic medium lacking leucine, verified by PCR with the flanking oligonucleotides 19.137/19.138 (Table 1) and subjected to tetrad analysis to yield haploid segregants carrying the deletion. In order to assess the biological function of heterologously expressed ZWF1 homologs, HOD408 (MATa/MAT $\alpha$ ura3-52/ura3-52 leu2-3,112/leu2-3,112 his3-11,15/his3-11,15 RPE1/rpe1::KILEU2 zwf1::kanMX/ZWF1) was then constructed by crossing. This diploid strain, which is heterozygous for both the zwf1 and the rpe1 deletion, was used as a recipient for transformation with different plasmids carrying URA3 as a selection marker. Transformants were sporulated and subjected to tetrad analysis. Growth of segregants carrying both deletion markers, kanMX and KlLEU2 together with the plasmid-borne URA3 gene, was taken as evidence that the respective heterologous gene can complement the zwf1 defect. In a similar fashion as described for RPE1, the yeast NQM1 gene was substituted by the KlLEU2 marker by a PCR product obtained from pJJH1287 with the primers 19.143/19.144 in the diploid strain DHD5. Transformants verified with the flanking primers 19.141/19.142 were sporulated and subjected to tetrad analysis to obtain a haploid segregant carrying the $n q m 1$ deletion for crossing with the zwf1 deletion.

Plasmids expressing ZWF1 from S. cerevisiae or its homologs from other organisms were obtained by cloning either PCR products (for S. cerevisiae and K. lactis) or synthetic DNA-fragments under the control of a modified constitutive PFK2 promoter into the centromeric plasmid pJJH2064 [51]. Plasmids employed with their pJJH numbers are listed in Table 2, and their complete sequences are available upon request. Specifically, to clone the ZWF1 genes encoding the two yeast enzymes, the one from S. cerevisiae was amplified by PCR with the primer pair 16.234/17.036, and the one from the milk yeast Kluyveromyces lactis with the primer pair 17.309/18.002 (see Table 1 for oligonucleotide sequences), both using genomic DNA prepaired from the respective strains as template. For cloning of heterologous G6PD genes, their coding cDNA sequences were obtained (accession numbers given in Table 2) and synthesized in the yeast codon usage (Thermo Scientific GeneArt synthesis), introducing a unique BamHI site prior to the ATG start and a unique HindIII site following the translation stop codon. Mutations leading to exchanges of specific amino acid residues in the encoded proteins for AtG6PD1 were also introduced by synthesis of DNA fragments with convenient restriction sites for cloning into the original plasmids carrying the respective wild-type genes. All open reading frames were verified by Sanger sequencing (Seqlab, Göttingen, Germany) prior to their introduction into the yeast recipient cells.

For detection in Western blot analyses, 3xHA-tags were introduced by in vivo-recombination into recipient plasmids linearized with HindIII, dephosphorylated with alkaline phosphatase and co-transformed with PCR products obtained from pFA6a-3HA-SkHIS3 [52] as a template for amplification with 17.046 as a primer with homologies to the vector sequences located $3^{\prime}$ to the genes and the appropriate primers generating in-frame fusions to the respective ORFs, as listed in Table 1. 
Table 1. Oligonucleotides used in this work.

\begin{tabular}{|c|c|}
\hline Name (Number) & Sequence $\left(5^{\prime} \rightarrow 3^{\prime}\right)$ \\
\hline ZWF1atgforBam (16.234) & ggcgggatccATGAGTGAAGGCCCCGTCAAATTCG \\
\hline ZWF1revHind (17.036) & gcgtgaaagcttGATAAGTACAAGTCCAATCGGACTG \\
\hline KIZWF1ATGforBam (17.309) & ctacaggatccATGGCTACTCAGTTTGACGAGAAC \\
\hline K1ZWF1revwoBam (18.002) & $\begin{array}{l}\text { acacaggaaacagctatgaccatgattacgccaagcttTTACATTTTAGGAGTGGTGACAGGCCATTGGTAG } \\
\text { ctTCCTGGTTTGGAAAAGG }\end{array}$ \\
\hline 2064rev3HA (17.046) & acaatttcacacaggaaacagctatgaccatgattacgccaagcttAGGGAGACCGGCAGATCCGCGG \\
\hline ScZWF1for3HA (18.200) & ttacgcttggeccgtgactaagccagaagatacgaaggataatCGGATCCCCGGGTTAATTAA \\
\hline K1ZWF1for3HA (18.202) & aaaccaggaagctaccaatggectgtcaccactcctaaaatgCGGATCCCCGGGTTAATTAA \\
\hline HsG6PD1for3HA (18.205) & ttcaatacgagggtacttacaaatgggttaatccacacaagctgCGGATCCCCGGGTTAATTAA \\
\hline EcZWF1for3HA (18.201) & gatgattacccgtgatggtcgttcctggaatgagtttgagCGGATCCCCGGGTTAATTAA \\
\hline AtG6PD1for3HA (18.199) & ttctaagtataacgttagatggggtgacttgggtgaagcaCGGATCCCCGGGTTAATTAA \\
\hline AtG6PD5for3HA (18.203) & tacatgcaaacccatggttacatttggattccaccaactttgCGGATCCCCGGGTTAATTAA \\
\hline AtG6PD6for3HA (18.204) & ttacttgcaaacccatggttatatttggattccaccaaccttgCGGATCCCCGGGTTAATTAA \\
\hline Sczwf1del5 (16.235) & atgagtgaaggccccgtcaaattcgaaaaaaataccgtcatatCTTCGTACGCTGCAGGTCGAC \\
\hline Sczwf1del3 (16.236) & ctaattatccttcgtatcttctggcttagtcacgggccaaGCATAGGCCACTAGTGGATCTG \\
\hline ScZWF1forSac (16.232) & gcgtgagctCCTGGTAAGTAAGGTGTAGTTTTG \\
\hline ScZWF1revSal (16.233) & gtgagtcgacGATAAGTACAAGTCCAATCGGACTG \\
\hline Scrpe1del5 (19.139) & aagaaggccatttgctaattccaagagcgaggtaaacacacaagaaaaaCTTCGTACGCTGCAGGTCGAC \\
\hline Scrpe1del3 (19.140) & tatcgtatagtatagagagtataaatataagaaatgccgcatatgtacaaGCATAGGCCACTAGTGGATCTG \\
\hline ScRPE1forBam (19.137) & CTCGTGgatCCAATAATGAAACTGAAAAGCATG \\
\hline ScRPE1revHind (19.138) & AAAGAAGcTTCTTTGACTTTGGTTAAGG \\
\hline Scnqm1del5 (19.143) & cgtaagtcataaaaaataggaaataatcacatatatacaagaaattaaatCTTCGTACGCTGCAGGTCGAC \\
\hline Scnqm1del3 (19.144) & tggtatatatatatttatatatataagtaggtacctctactcttaatgaGCATAGGCCACTAGTGGATCTG \\
\hline ScNQM1forXho (19.141) & GCAATCTCGAGAACAATTGCAGGACAGG \\
\hline ScNQM1revSac (19.142) & gtacggagcTCGGAATTTGATTATACGTCAG \\
\hline
\end{tabular}

Nucleotide sequences complementary to the template for PCR reactions are given in capital letters, others in small letters. If the latter comprise more than 35 nucleotides, they provide the region for homologous recombination of the PCR product with the target sequences either in the vector (for 3HA tags) or the yeast genome (for construction of deletions). Restriction sites introduced with the primers into the PCR product are underlined. "for" and "rev" in the name, designating the respective forward and reverse primers for each pair. All forward primers used for tagging with 3HA were employed in conjunction with 2064revHA (17.046) to obtain PCR products suitable for recombination with the target vectors listed in Table 2. AtG6PD1for3HA (18.205) was used to tag the wild-type gene as well as the three mutant variants constructed. For cloning of KlZWF1, the reverse primer was designed to elimate an internal BamHI site of the gene by silent nucleotide exchanges (indicated by the small letters ct in the run of capital letters). "del5" and "del3" designate the forward and reverse primers for deletion of the respective genes.

\subsection{Enzyme Assays and Western Blot Analysis}

Glucose-6-phosphate dehydrogenase activities were determined routinely from yeast crude extracts prepared by breaking of cells with glass beads and centrifugation, as described previously [53]. Alternatively to the preparation of crude extracts from fresh overnight cultures, we verified that specific G6PD activities did not suffer from freezing the washed harvested cells at $-20^{\circ} \mathrm{C}$ for several days. Glass beads were then added to the frozen pellet and preparation of crude extracts followed the standard protocol from then on. Tris- $\mathrm{HCl}$ buffer, $\mathrm{pH} 7.5$, was employed for preparation of crude extracts and enzymatic determinations. G6PD activities were determined by following the kinetics of 
NADP reduction at a final concentration of $0.4 \mathrm{mM}$, added from a $40 \mathrm{mM}$ stock solution in extraction buffer, in a DU800 spectrophotometer (Beckman-Coulter, Krefeld, Germany) at $340 \mathrm{~nm}$ and $30{ }^{\circ} \mathrm{C}$. Glucose-6-phosphate was added as a substrate at a final concentration of $2 \mathrm{mM}$, after determination of the extinction difference obtained by crude extract in the absence of the substrate. For treatment with dithiothreitol (DTT), $2 \mu \mathrm{L}$ of a $100 \mathrm{mM}$ stock solution was added to $200 \mu \mathrm{L}$ of crude extract and incubated for $20 \mathrm{~min}$ at room temperature prior to enzymatic determinations. Likewise, diamide was added to a $200 \mu \mathrm{L}$ aliquot of crude extract at a final concentration of $0.5 \mathrm{mM}$ for $20 \mathrm{~min}$ at room temperature to provide an oxidative environment. All chemicals used for enzyme tests were obtained from Sigma-Aldrich Chemie GmbH, Munich, Germany.

For Western blot analyses, crude extracts prepared as above were mixed with SDS sample buffer (final concentrations: $60 \mathrm{mM}$ Tris/ $\mathrm{HCl}, \mathrm{pH}$ 6.8, 10\% glycerol, 2\% SDS, 0.005\% Bromphenol Blue) and heated to $98^{\circ} \mathrm{C}$ for $5 \mathrm{~min}$, prior to separation on precast $10 \%$ SDS-polyacrylamide gels (LTF-Labortechnik $\mathrm{GmbH}$ and Co KG Wasserburg, Germany). Blotting and preparation for immunological detection was done as explained in [54]: after completion of electrophoresis, gels were transferred to a nitrocellulose membrane (Whatman GmbH, Dassel) with the "Trans-Blot SD Semi-Dry Electrophoretic Transfer Cell" (Bio-Rad). Membranes were blocked for 1 to $3 \mathrm{~h}$ at room temperature with TBST (20 mM Tris, $150 \mathrm{mM}$ $\mathrm{NaCl}, \mathrm{pH}$ adjusted to 7.6 with $\mathrm{HCl}, 0.05 \%$ Tween 20 ) containing 3\% bovine serum albumin (BSA, Roth, Karlsruhe, Germany). 3xHA-labelled G6PD enzymes were detected with an anti-HA mouse antibody (kindly provided by Anja Lorberg, Osnabrück), which was diluted 1:10000 in TBST with 3\% BSA. An anti-mouse antibody from goat coupled to IRDye 800CW (Li-Cor Biosciences, Lincoln, NE, USA; diluted 1:5000 in TBST with 3\% BSA) was used as a secondary antibody. As an internal loading control, the phosphofructokinase subunits were detected using an anti-PFK polyclonal antiserum from rabbit at a dilution of 1:10.000 [55], and an anti-rabbit IgG antibody from donkey coupled to IRDye 700DX (Rockland Immunochemicals, Gilbertsville, PA, USA, diluted 1:5000 with 3\% BSA in TBST) as a secondary antibody. The Odyssey infrared imaging system was used for detection and quantification of signals (LI-COR Biosciences GmbH, Bad Homburg, Germany). For quantification, G6PD signals were determined relative to the control PFK signals. ScZwf1 (G6PD from S. cerevisiae) was set at $100 \%$ and normalized signals from the heterologous enzymes were calculated as percentages of this value.

\subsection{Determination of Chronological Life Span}

Precultures of cells of strain HD269-1C carrying CEN/ARS plasmids with the genes indicated were grown overnight at $30^{\circ} \mathrm{C}$ in $2.5 \mathrm{~mL}$ of SCD medium lacking uracil for plasmid selection to reach an early stationary phase. They were diluted 200-fold in $25 \mathrm{~mL}$ of fresh medium in $100 \mathrm{~mL}$ Erlenmeyer flasks and further incubated with agitation $(180 \mathrm{rpm} / \mathrm{min})$ for 2-3 days until they reached the stationary phase. Samples were then taken for a total of two weeks at the times indicated, appropriately diluted to yield 50-500 viable cells per $100 \mu \mathrm{L}$ and plated onto YEPD. The number of viable cells per mL of culture was then calculated from colony counts (colony forming units, CFU) after 3 days of incubation at $30{ }^{\circ} \mathrm{C}$. CFUs determined at day 0 were set at $100 \%$ for each culture. CFUs obtained at each time point were then related to this value. Each clone was inoculated in triplicate and mean percentages of survival and standard deviations were calculated from these biological replicates.

\section{Results}

\subsection{A Yeast System for Heterologous Expression of G6PD Genes}

In order to establish a versatile expression system for G6PD genes from organisms spanning the kingdoms of bacteria, fungi, plants, and animals, we obtained a deletion mutant in the sole S. cerevisiae ZWF1 gene, substituting its open reading frame (ORF) for a kanMX deletion cassette in one allele of the wild-type diploid strain DHD5 (Figure 1A). To assess the growth phenotypes of haploid segregants carrying the zwf1 deletion, the diploid was subjected to tetrad analysis and spores were allowed to germinate and grow on rich medium with $2 \%$ glucose as a carbon source. In contrast 
to previous reports, we noted a distinct growth retardation associated with the zwf1 deletion in this strain background. Thus, a 2:2 segregation for large and small colonies was observed, with the smaller colonies invariably carrying the zwf1 deletion allele, as confirmed by their resistance towards G418 (Figure 1B). This phenotype was not rescued by the addition of methionine to the rich medium, for which zwf1 deletions have been reported to be auxotrophic (Figure 1B). One segregant from such an analysis, HOD269-1C, was then chosen for further investigations described below.
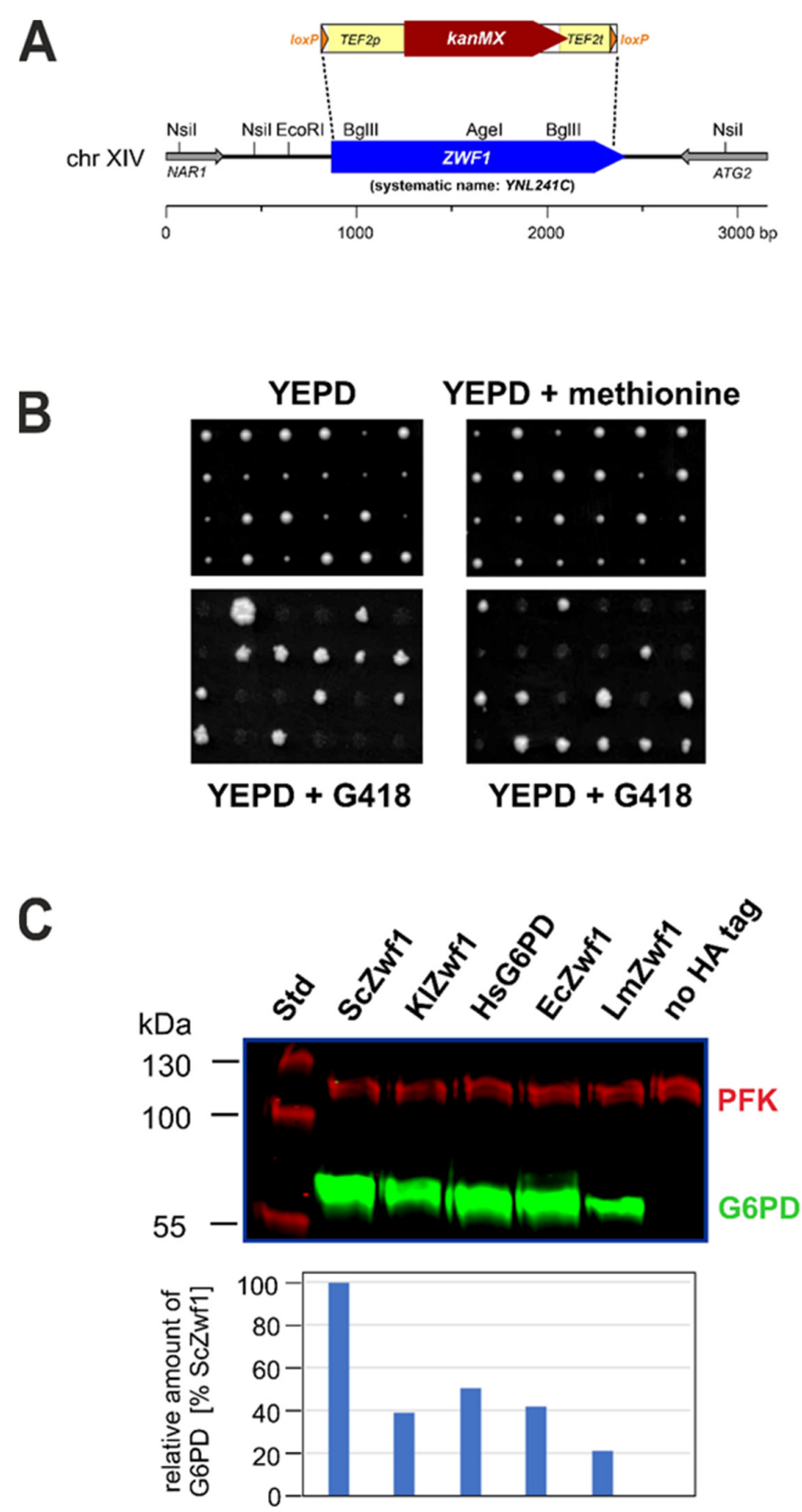

Figure 1. Construction of a yeast $z w f 1$ deletion strain, growth phenotypes and analysis of heterologously produced G6PD enzymes. (A) Schematic respresentation of the wild-type ZWF1 locus of Saccharomyces cerevisiae on chromosome 14 and strategy for its substitution by a kanMX marker cassette. Grey arrows respresent flanking genes, the blue arrow the open reading frame of ZWF1. Some common restriction sites are shown above. The deletion cassette depicted at the top is flanked by loxP sites as targets for the Cre recombinase. (B) Tetrad analysis of the heterozygous strain HOD269 (ZWF1/zwf1::kanMX) on rich medium (left upper picture) and rich medium supplemented with methionine. The lower panels 
show growth after replica-plating onto rich medium supplemented with $200 \mathrm{mg} / \mathrm{L}$ of G418 (geneticin). Six representative tetrads are shown for each analysis, out of a total of at least 18 tetrads analyzed. (C) Western blot analysis of crude extracts from strain HOD269-1C (zwf1::kanMX) carrying the genes indicated on a CEN/ARS vector. The upper picture shows the results of the blot analyzed with the Odyssey scanner with anti-PFK shown in red and anti-HA detecting the tagged G6PD enzymes in green. Columns in the lower picture show the quantification of G6PD signals normalized to the amount of PFK detected for each lane in the Western blot, setting ScZwf1 at 100\%.

\subsection{Heterologous G6PD Genes from Different Biological Kingdoms Complement a Yeast zwf1 Deletion}

The zwf1 mutant thus constructed was then used as a recipient for heterologous expression of genes encoding G6PD isozymes throughout the biological kingdoms, as listed in Table 2. After the preparation of crude extracts from strains carrying the genes on the CEN/ARS vector pJJH2064 under the control of the constitutive PFK2 promoter, specific G6PD activities were determined and demonstrated the functional expression of genes from the closely related yeast Kluyveromyces lactis, the bacteria Escherichia coli and Leuconostoc mesenteroides, different isozymes of the plant Arabidopsis thaliana, and the human G6PD gene (Table 2).

Table 2. Genes expressed in a yeast zwf1 deletion and specific G6PD activities.

\begin{tabular}{|c|c|c|c|c|}
\hline Strain/Plasmid & Gene & Source Organism & Accession Number ${ }^{1}$ & $\begin{array}{l}\text { Specific Activity }^{2} \\
{[\mathrm{mU} / \mathrm{mg} \text { Protein] }}\end{array}$ \\
\hline HD56-5A/pJJH2064 & ZWF1 (wt) & Saccharomyces cerevisiae & $\begin{array}{c}\text { CP046094.1 } \\
\text { GI:1789112053 }\end{array}$ & $99.33 \pm 2.47$ \\
\hline HOD269-1C/pJJH2064 & vector & - & - & $<0.5$ \\
\hline HOD269-1C/pJJH2111 & ScZWF1 & $\begin{array}{l}\text { Saccharomyces cerevisiae } \\
\text { (strain CEN.PK113-7D) }\end{array}$ & $\begin{array}{c}\text { CP046094.1 } \\
\text { GI:1789112053 }\end{array}$ & $312.92 \pm 26.60$ \\
\hline HOD269-1C/pJJH2292 & KlZWF1 & Kluyveromyces lactis & $\begin{array}{l}\text { NC_006040.1 } \\
\text { GI: } 50313009\end{array}$ & $134.43 \pm 14.67$ \\
\hline HOD269-1C/pJJH2223 & HsG6PD1 & Homo sapiens & $\begin{array}{l}\text { BC000337.2 } \\
\text { GI: } 33991065\end{array}$ & $89.03 \pm 5.86$ \\
\hline HOD269-1C/pJJH2249 & AtG6PD6 & Arabidopsis thaliana & $\begin{array}{l}\text { NM_113644.5 } \\
\text { GI: } 1063714071\end{array}$ & $24.38 \pm 4.96$ \\
\hline HOD269-1C/pJJH2494 & EcZWF1 & Escherichia coli $\mathrm{K} 12$ & $\begin{array}{c}\text { CP047127.1 } \\
\text { GI: } 1789840096\end{array}$ & $20.28 \pm 1.05$ \\
\hline HOD269-1C/pJJH2495 & $L m Z W F 1$ & Leuconostoc mesenteroides & M64446.1 & $52.01 \pm 1.07$ \\
\hline
\end{tabular}

${ }^{1}$ Nucleotide sequences for ScZWF1, KIZWF1 and EcZWF1 were extracted from the genome sequences with the given accession numbers from Genbank. Other accession numbers refer to mRNA sequences. All sequences were codon-optimized and synthesized for expression in S. cerevisiae, without changes in the primary amino acid sequences of the encoded proteins. ${ }^{2}$ Specific activities were obtained from at least three independent cultures each, with at at least three technical replicates of enzyme measurements for each crude extract. \pm designate the standard deviations. ${ }^{3}$ For expression in S. cerevisiae the AtG6PD1 gene was synthesized omitting the first 50 codons for the plastidic signal sequence of the protein, starting after an initiating methionine with the amino acid residues FFAEKHSQ.

The considerable variations in the specific activities of the heterologous enzymes raised the questions of whether i) the genes were properly expressed, and ii) the encoded proteins were stably produced in the yeast $z w f 1$ deletion. Therefore, all encoded proteins were equipped with a C-terminal 3xHA-tag and subjected to a Western blot analysis, using the heterooctameric yeast glycolytic enzyme phosphofructokinase as a loading control and reference for quantification [55]. It should be noted that specific G6PD activities were not notably affected by the C-terminal tags as compared to those reported in Table 2, whereas the introduction of the same tags at the $\mathrm{N}$-terminus caused a complete 
loss of enzymatic activity in all cases. As shown in Figure $1 \mathrm{C}$, the C-terminally tagged heterologous enzymes of all but the plant enzymes were produced at approximately half the levels of the native ScZwf1-3HA, with the exception of the one from L. mesenteroides, which reached only $20 \%$ (protein levels of strains expressing the $A$. thaliana enzymes are discussed below in Section 2.3).

We proceeded by determining the physiological consequences of heterologous G6PD gene expression in the yeast $z w f 1$ deletion. For this purpose, the hypersensitivity of the deletion towards oxidative stress exerted by the addition of hydrogen peroxide to the medium was employed $[30,31,56]$. Drop dilution assays confirmed that viability of the deletion carrying the expression vector lacking any G6PD sequence was strongly impaired in the presence of hydrogen peroxide as compared to the control plate without the stressor or the strain carrying the plasmid with the wild-type ZWF1 gene (Figure 2). Complementation ability of the heterologous genes largely correlated with the specific activities measured in the crude extracts of the respective strains, with KlZWF1 and HsG6PD1 displaying growth like the wild-type, and the AtG6PD genes and EcZWF1 conferring intermediate viability. As an exception, the gene from L. mesenteroides appears to lack complementation despite the detectable specific activity in crude extracts.

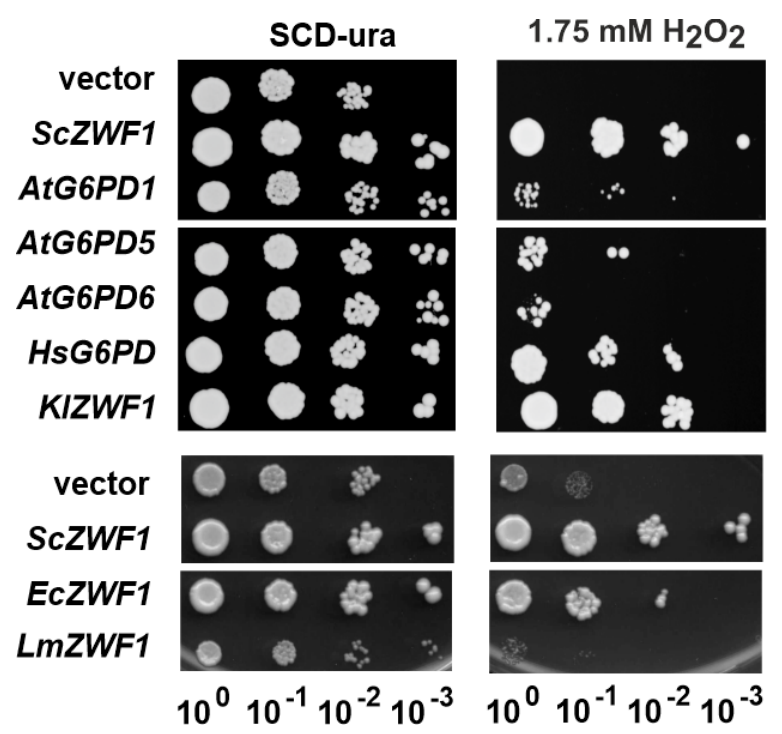

Figure 2. Drop dilution assays of a yeast zwf1 deletion strain expressing heterologous G6PD genes. Logarithmically growing cultures of strain HOD269-1C (zwf1::kanMX) carrying the genes indicated on a CEN/ARS vector were diluted in fresh selective medium to an OD600 $=0.1$ and subjected to ten-fold serial dilutions as indicated below.A quantity of $3 \mu \mathrm{L}$ of each dilution was dropped onto the plates indicated and growth was documented after 3 days incubation at $30^{\circ} \mathrm{C}$.

In order to obtain a more stringent phenotype for the assessment of heterologously expressed genes, we further confirmed that the zwf1 deletion showed synthetic lethality with an rpe1 deletion in the genetic background of the strain used herein. Therefore, HOD269-1C (zwf1::kanMX) was crossed to an isogenic HD56-5A derivative, in which RPE1 was substituted by a heterologous marker from Kluyveromyces lactis (rpe1::KlLEU2), and subjected to tetrad analysis. While segregants of the resulting diploid HOD408 showing resistance to G418 and segregants prototrophic for leucine were readily obtained, double deletions displaying both markers did not produce any viable progeny (Figure 3A). In contrast, a combination of $z w f 1$ with a nqm1 deletion, which lacks a paralog of transaldolase of unknown function and was also reported in the Saccharomyces genome database (https://www.yeastgenome.org; searched on November 7, 2019) to be synthetically lethal, could not be confirmed, since segregants carrying the double deletions produced viable progeny (Figure 3B). HOD408 was then used as a recipient for plasmids carrying some of the heterologous genes and transformants were sporulated and again subjected to tetrad analyses (Figure 3C). Viability of segregants carrying both deletion markers 
(zwf1::kanMX rpe1::KlLEU2) in conjunction with URA3 as an indicator of the presence of the respective plasmid confirmed that the wild-type ZWF1 gene (pJJH2111) from S. cerevisiae restored growth to the double deletion, as did the human gene (HsG6PD1 on plasmid pJJH2223) and AtG6PD1 (pJJH2125). The latter produced smaller colonies in accordance with its limited capacity to complement the $z w f 1$ deletion. Neither of the respective segregants grew on medium containing 5-FOA, an antagonist toxic to strains with a wild-type URA3 gene, confirming that growth depended on the presence of the plasmid. In contrast, no viable segregants of the double deletions were obtained from diploids transformed with pJJH2064 (empty vector) or pJJH2495 (LcZWF1).

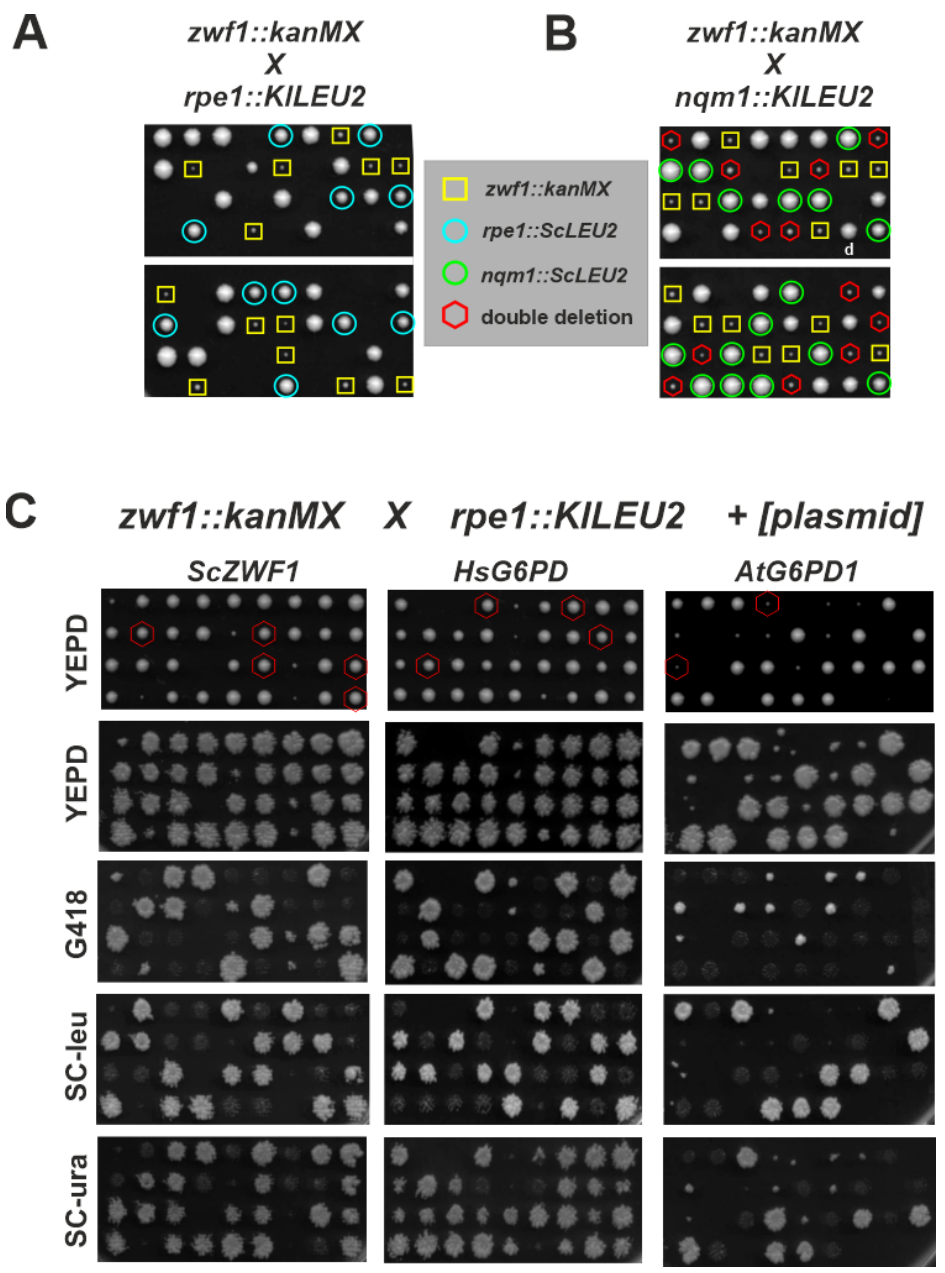

Figure 3. Analysis of synthetic lethality of a yeast $z w f 1$ deletion and complementation by heterologously expressed genes. Strain HOD269-1C (zwf1::kanMX) was crossed to isogenic strains carrying either a rpe1 deletion (A) or a $n q m 1$ deletion (B) and subjected to tetrad analyses on rich medium. Growth was documented after 3 days of incubation at $30^{\circ} \mathrm{C}$. Colored circles and squares highlight single- and double-deletion mutants as indicated. (C) The heterozygous diploid strain HOD408 (ZWF1/zwf1::kanMX RPE1/rpe1::KlLEU2) was transformed with CEN/ARS plasmids carrying the genes indicated, sporulated and subjected to tetrad analyses on rich medium (upper pannels). Growth was documented after 3 days of incubation at $30^{\circ} \mathrm{C}$, before replica-plating onto the indicator media shown in the lower pannels. Growth there was documented after 1-2 days of incubation at $30^{\circ} \mathrm{C}$. Red circles indicate viable double deletions complemented by the plasmid-encoded gene.

\subsection{Mutational Analysis of Plant G6PD1}

Results on complementation of the slow-growth phenotype of the yeast zwf1 mutant and of the specific enzyme activities reported above indicated that G6PD1 from A. thaliana lacking its plastidic 
signal sequence (see legend of Table 2 for details) is barely functional in the heterologous expression system. Since this might be attributed to an inefficient formation of disulfide bridges in the cytoplasm of yeast as opposed to chloroplasts in plant cells, we intended to substitute the two cysteine residues involved by a salt bridge, i.e., the two cysteines were substituted by an aspartate and a lysine residue, respectively (AtG6PD1 ${ }^{\mathrm{C} 100 \mathrm{D} / \mathrm{C} 108 \mathrm{~K}}$ ). Indeed, the respective plasmid was able to rescue the growth defect of the yeast $z w f 1$ mutant in the presence of hydrogen peroxide much better than the one with the original AtG6PD1 clone, as demonstrated by drop dilution assays (Figure 4A). However, to our surprise, the increased complementation capacity was also observed for clones in which only the first cysteine residue was substituted for an alanine (AtG6PD1 ${ }^{\mathrm{C} 100 \mathrm{~A}}$ ), or in a mutant with an alanine-lysine combination (AtG6PD1 ${ }^{\mathrm{C} 100 \mathrm{~A} / \mathrm{C} 108 \mathrm{~K}}$ ), not expected to form a salt bridge. This result indicated that it is rather the formation of a disulfide bridge than its absence, which is deleterious for the function of the enzyme in yeast. This cannot be attributed to a stabilization of the mutant proteins in vivo, since they display slightly decreased steady-state levels as compared to the wild-type, as judged from their 3xHA-tagged variants in a Western blot analysis (Figure 4B).

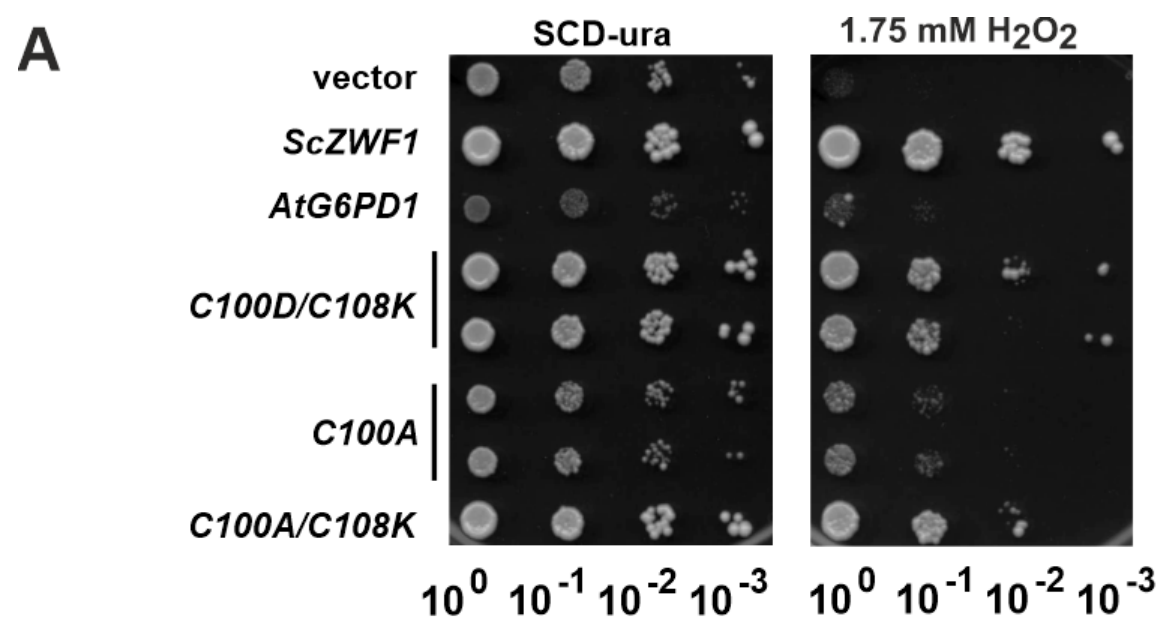

B

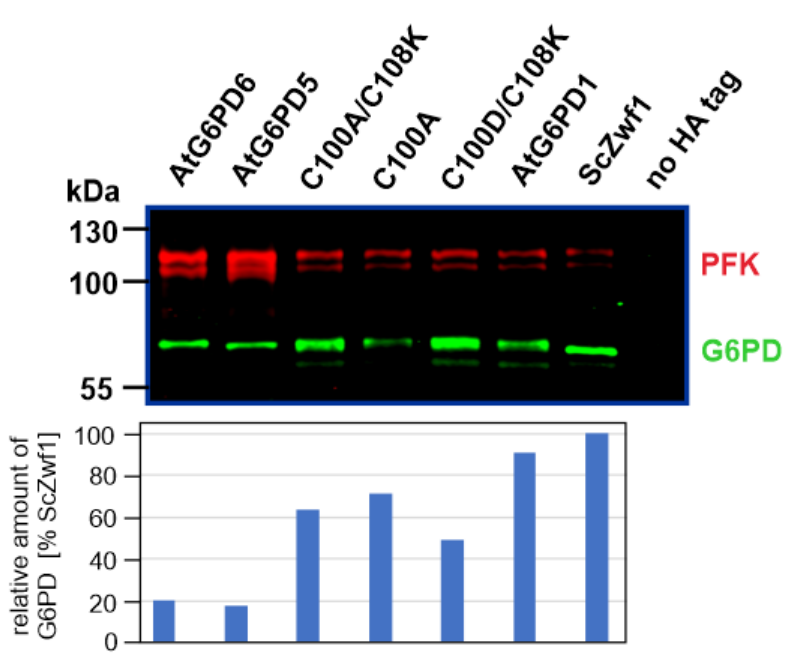

Figure 4. Cont. 
C

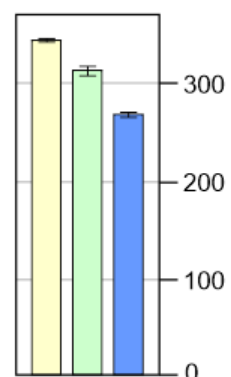

ScZwf1

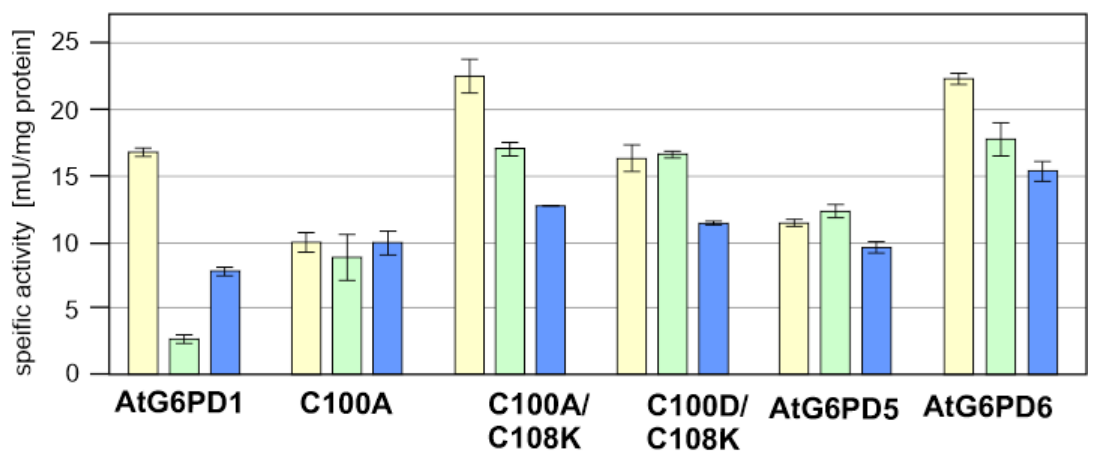

$0.5 \mathrm{mM}$ diamide

Figure 4. Analysis of a yeast zwf1 deletion producing different G6PD isoforms from Arabidopsis thaliana. (A) Logarithmically growing cultures of strain HOD269-1C (zwf1::kanMX) carrying either the wild-type AtG6PD1 gene or the mutated variants indicated on a CEN/ARS vector were subjected to drop dilution assays and analyzed as explained in the legend of Figure 2. Strains carrying the empty vector or a plasmid with the native ScZWF1 gene were employed as controls. (B) Western blot of crude extracts from strains producing the indicated AtG6PD isoforms. Antisera and quantification were as explained in the legend of Figure 1C, setting the amount of ScZwf1 to 100\%. (C) Sensitivity of different G6PD enzymes produced in the yeast $z w f 1$ deletion strain towards reductive (DTT) and oxidative (diamide) conditions. Specific enzyme activities were either directly determined after preparation of crude extracts (yellow columns) or after pre-treatment of the same crude extracts with $1 \mathrm{mM}$ DTT (green columns) or $0.5 \mathrm{mM}$ diamide (blue columns). Activities were at least determined in triplicate, with the error bars giving the standard deviations of these technical replicates.

In order to assess the influence of the redox environment on the activity of the AtG6PD1 variants and the other enzymes from $A$. thaliana investigated herein, we determined the specific activities in crude extracts treated with either dithiothreitol (DTT) or diamide as reductive or oxidative conditions, respectively. As expected from previous data on the plant enzyme [17], AtG6PD1 activity depended on its redox state and its activity decreased significantly when incubated with DTT, while those of AtG6PD5 and AtG6PD6 did not (Figure 4C). The yeast G6PD, which was employed as a control, was insensitive to DTT treatment, too. Treatment with diamide generally led to a moderate reduction in specific activities, indicating that the stability of all enzymes in the yeast crude extracts was slightly affected.

\subsection{Chronological Life Span of S. cerevisiae Is Drastically Reduced by the zwf1 Deletion and Restored by Heterologous Expression of Functional ZWF1 Homologs}

In the course of inoculating the zwf1 deletion strain carrying the vector pJJH2064 without an insertion for several controls, we noticed that they did not survive prolonged periods of storage at $4{ }^{\circ} \mathrm{C}$, in contrast to those carrying the wild-type ScZWF1 gene. Therefore, the chronological life span of a strain lacking its native glucose-6-phosphate dehydrogenase was investigated and compared to a wild-type strain carrying the vector, and the deletion strain carrying eiher an episomal native ScZWF1 gene, or the ones encoding the human G6PD1 or the isoform 1 of A. thaliana. As evident from Figure 5, the deletion strain lacking G6PD activity rapidly lost viability and formed less than 1\% of the colonies counted for the original stationary phase culture within four days of incubation. On the other hand, all other transformants showed a life span comparable to wild-type cells, displaying more than $80 \%$ viability after 4 days and taking at least 11 days to decrease to less than $1 \%$. However, it should be noted that the lifespan of the clone carrying the AtG6PD1 gene appeared to be somewhat reduced as compared to the ones carrying either ScZWF1 or the human homolog. 


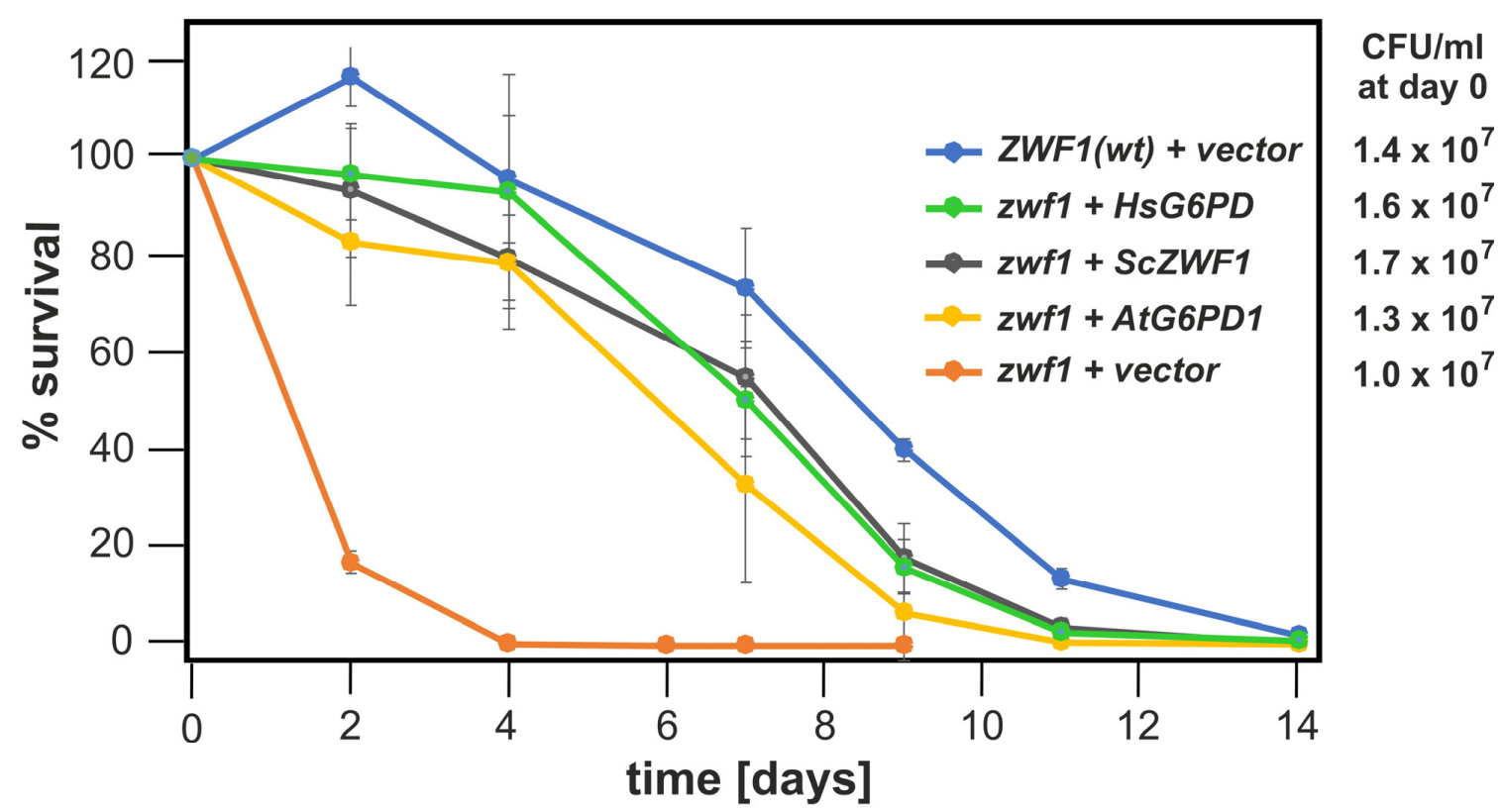

Figure 5. Chronological lifespan of a yeast $z w f 1$ deletion expressing heterologous G6PD genes. The indicated plasmids were introduced into strain HOD269-1C (zwf1::kanMX) and cultures were grown to stationary phase in synthetic selective medium. Samples were taken at the time points indicated, appropriately diluted to produce single colonies, plated on rich medium and incubated for three days prior to determination of colony-forming units (CFU). CFUs were set at $100 \%$ at day 0 , with starting counts indicated at the upper-right corner, and relative viability was determined in three independent cultures, each. Error bars give the standard deviations of \% survivors in these three biological replicates.

\section{Discussion}

In this work, we constructed a deletion mutant of the gene ZWF1, encoding the unique glucose-6-phosphate dehydrogenase enzyme (G6PD) in the yeast Saccharomyces cerevisiae to assess its suitability as a host for heterologous expression of G6PD homologs from various organisms throughout the biological kingdoms, in order to study their molecular structure and biochemical properties. Unexpectedly, we noted a distinct growth retardation of haploid deletion strains on standard media. This stands in contrast to data on $z w f 1$ deletions in most other yeast strains, which were reported to grow as wild-type under such conditions [30-32,56]. However, the zwf1 deletion was lethal in another common background of strain $\Sigma 1278 \mathrm{~b}$ [57], underlining the substantial degree of nucleotide polymorphisms observed between commonly employed yeast strains [45]. The intermediate phenotype of the deletion strain used herein thus combines the advantage of being viable with that of reflecting the complementation capacity of heterologously expressed G6PD genes directly by the size of the colonies produced upon transformation. A more stringent test for complementation of growth phenotypes is provided by the hypersensitivity of zwf1 deletions towards oxidative stress, which is shared by our mutant with all viable strains tested in the works cited above. Moreover, we confirmed the synthetic lethality of the zwf1 deletion with that of the RPE1 gene [58] in our strain background as yet another means to test for complementation capacity. On the other hand, zwf1 nqm 1 double deletions did not excerbate the growth retardation of single $z w f 1$ deletions, i.e., they did not display a synthetic defect. This could be explained by the role of the ribulose-5-phosphate-3-epimerase encoded by RPE1 in the non-oxidative part of the pentose phosphate pathway, thus rendering both parts of the pathway non-functional in the zwf1 rpe1 double deletion. We, therefore, conclude that the PPP serves essential functions in S. cerevisiae, which can be met by either the oxidative or the non-oxidative part through their connections with glycolysis, but not if the two branches are blocked. Accordingly, NQM1 is supposed to encode a transaldolase of unknown function, which obviously is not required for the non-oxidative PPP, were the TAL1-encoded transaldolase works. 
Another phenotype observed for the zwf1 deletion employed in this work is the drastic reduction in chronological lifespan (CLS), which is also alleviated by the expression of heterologous G6PD genes from humans and plants. This phenotype is most likely related to the fact that the production of reactive oxygen species (ROS) is a primary cause of ageing from yeast to humans [59], and the G6PD reaction provides the NADPH for its detoxification [3,4]. That CLS has not been assessed for $z w f 1$ deletions in yeast until now may be attributed to the lack of growth phenotypes under standard conditions discussed above. Our findings thus also provide the basis to study the contribution of G6PD enzymes to ageing in the genetically easily tractable yeast model.

Although all heterologously expressed G6PD genes herein complemented the yeast zwf1 deletion, they did so in various degrees, judging from the two parameters of specific enzyme activity and growth of the transformants in the presence of hydrogen peroxide. These two parameters did not always correlate. For instance, the three isoforms of AtG6PD barely conferred growth to the respective transformants in the presence of oxidative stress, whereas the bacterial enzyme from L. mesenteroides did not. Yet, the latter had specific activities that were at least double those of the plant enzymes measured in crude extracts from such transformants. On the other hand, specific activities of G6PD from E. coli were in the lower range of those of the plant isozymes, but transformants grew almost like wild-type controls in the presence of hydrogen peroxide. Differences in the growth complementation assays could also not be explained by varying stabilities of the enzymes produced in the yeast recipient strain, since Western blots showed higher steady-state levels for the HA-tagged plant isozymes, which did not complement well, than for the enzyme from the closely related milk yeast K. lactis, which did. We conclude that the cytosolic environment within the yeast cell substantially affects the actual in vivo activity of the heterologously produced G6PD chloroplast proteins, as observed in plants [18]. Clearly, the enzymes from human and yeasts work best, followed by the one from E. coli and the plant isozymes. The lack of complementation by the other bacterial G6PD, LmZwf1, despite its high specific activity in crude extracts can be attributed to its special cofactor dependence. While all the other enzymes tested herein exclusively use NADP as a cofactor, the enzyme from L. mesenteroides is less specific and can also employ NAD [60,61]. Since $S$. cerevisiae does not have a transhydrogenase which could interconvert the reduced forms of these cofactors [62], we assume that redox balance under oxidative stress is severely impaired by the production of this rather unusual heterologous enzyme. The fact, that transformants of the yeast zwf1 deletion with LmZWF1 produce even smaller colonies than those with the empty vector indicates that the heterologous enzyme exerts a negative effect already under standard growth conditions.

With regard to the AtG6PD1 isoform of A. thaliana, we reasoned that it may not properly form the disulfide bridge in the yeast cytosol, which appears to be crucial in plant chloroplasts for its activity in the dark phase [16]. Although the attempt to substitute the disulfide by an ionic bridge appeared to improve the complementation capacity of the enzyme at first glance, further mutant analyses indicated that the reason for this was rather the lack than the presence of the bridge. As the wild-type AtG6PD enzyme displayed higher steady-state levels in the Western blots of HA-tagged variants, the improved complementation capacity cannot be attributed to enhanced protein stability in the yeast host. Since specific activities in crude extracts were also not drastically changed by the mutations, it must be the interplay of enzyme structure and activity in the yeast cytosol in vivo that causes better performance. Nevertheless, the observation that the activity of the wild-type AtG6PD1 isoform can be influenced by applying reducing conditions to the crude extracts, whilst the mutant enzymes incapable of forming a disulfide bridge do not react, underlines the suitability of the yeast expression system to assess the biochemical properties of single heterologously produced plant isoforms.

Finally, it should be noted that the manipulation of the ZWF1 gene in S. cerevisiae receives increasing attention for several biotechnological applications. Thus, the deletion of the gene improved ethanol production from xylose in a recombinant yeast strain, which was attributed to an increase in NADH production at the expense of NADPH [63]. Vice versa, overexpression of ZWF1 increased the resistance of a production strain towards furfural, an inhibitor present in the fermentation of 
lignocellulosic substrates [64]. The reaction is also required for the use of S. cerevisiae in fermentations to cope with the ROS produced in the presence of inhibitory phenolic compounds [65]. In addtion, overproduction of ZWF1 in combination with other genetic manipulations was employed to improve the production of isoprenoids and carotenoids in yeast [66,67], and a zwf1 deletion carrying the E. coli pyruvate dehydrogenase complex was found to accumulate cytosolic acetyl-CoA and thus may serve as an important platform strain for many biosynthetic processes, including the production of biobutanol [68]. In the context of such biotechnological uses, the substitution of the endogenous yeast G6PD by heterologous enzymes with altered biochemical properties, as demonstrated in this work, could well be an approach in metabolic design strategies.

\section{Conlcusions}

We demonstrated that the $z w f 1$ deletion obtained herein serves as a valuable expression system for heterologous G6PD genes in S. cerevisiae, especially when the presence of different isozymes impedes the biochemical analysis in the original host organism. Moreover, the relation of G6PD to oxidative stress response and ageing can be more conveniently studied in the extremely well-established model yeast. We, therefore, believe that this system will have broad applications not only in biotechnology, but also in medicine and agriculture.

Author Contributions: Conceptualization, J.J.H., J.K., and R.S.; Methodology, J.J.H., J.K., and R.S.; Software, J.J.H. and J.K.; Validation, J.J.H. and R.S.; Formal Analysis, J.J.H. and R.S.; Investigation, J.J.H.; Resources, J.J.H. and R.S.; Data Curation, J.J.H.; Writing-Original Draft Preparation, J.J.H.; Writing-Review \& Editing, J.J.H., J.K. and R.S.; visualization, J.J.H.; Supervision, J.J.H. and R.S.; Project Administration, J.J.H.; Funding Acquisition, J.J.H. and R.S. All authors have read and agreed to the published version of the manuscript.

Funding: This work was funded by sources provided by the University of Osnabrück to J.J.H. and to R.S..

Acknowledgments: We are grateful for excellent technical assistance in enzyme analyses and Western blotting provided by Andrea Murra. We also wish to thank Hans-Peter Schmitz for his invaluable help in quantification of the blotting data and his advise in statistics and bioinformatics, as well as Rosaura Rodicio for critical reading of the manuscript.

Conflicts of Interest: The authors declare no conflicts of interest.

\section{Abbreviations}

CLS chronological lifespan

G6PD glucose-6-phosphate dehydrogenase

DTT dithiothreitol

PPP pentose phosphate pathway

ZWF1 "Zwischenferment"; a synonym to G6PD from early metabolic analyses performed in the first half of last century

\section{References}

1. Ali, S.S.; Ahsan, H.; Zia, M.K.; Siddiqui, T.; Khan, F.H. Understanding oxidants and antioxidants: Classical team with new players. J. Food Biochem. 2020, e13145. [CrossRef] [PubMed]

2. Pugh, C.W.; Ratcliffe, P.J. New horizons in hypoxia signaling pathways. Exp. Cell Res. 2017, 356, 116-121. [CrossRef] [PubMed]

3. Yang, H.C.; Wu, Y.H.; Liu, H.Y.; Stern, A.; Chiu, D.T. What has passed is prolog: New cellular and physiological roles of G6PD. Free Radic. Res. 2016, 50, 1047-1064. [CrossRef] [PubMed]

4. Campbell, K.; Vowinckel, J.; Keller, M.A.; Ralser, M. Methionine metabolism alters oxidative stress resistance via the pentose phosphate pathway. Antioxid. Redox. Signal 2016, 24, 543-547. [CrossRef]

5. Grabowska, D.; Jablonska-Skwiecinska, E.; Plochocka, D.; Chelstowska, A.; Lewandowska, I.; Witos, I.; Majewska, Z;; Rokicka-Milewska, R.; Burzynska, B. A novel mutation in the glucose-6-phosphate dehydrogenase gene in a subject with chronic nonspherocytic hemolytic anemia-characterization of enzyme using yeast expression system and molecular modeling. Blood Cells Mol. Dis. 2004, 32, 124-130. [CrossRef] 
6. Mehta, A.; Mason, P.J.; Vulliamy, T.J. Glucose-6-phosphate dehydrogenase deficiency. Best Pract. Res. Clin. Haematol. 2000, 13, 21-38. [CrossRef]

7. Patra, K.C.; Hay, N. The pentose phosphate pathway and cancer. Trends Biochem. Sci. 2014, 39, 347-354. [CrossRef]

8. Riganti, C.; Gazzano, E.; Polimeni, M.; Aldieri, E.; Ghigo, D. The pentose phosphate pathway: An antioxidant defense and a crossroad in tumor cell fate. Free Radic. Biol. Med. 2012, 53, 421-436. [CrossRef]

9. Ho, H.Y.; Cheng, M.L.; Chiu, D.T. Glucose-6-phosphate dehydrogenase-Beyond the realm of red cell biology. Free Radic. Res. 2014, 48. [CrossRef]

10. Jain, M.; Brenner, D.A.; Cui, L.; Lim, C.C.; Wang, B.; Pimentel, D.R.; Koh, S.; Sawyer, D.B.; Leopold, J.A.; Handy, D.E.; et al. Glucose-6-phosphate dehydrogenase modulates cytosolic redox status and contractile phenotype in adult cardiomyocytes. Circ. Res. 2003, 93, e9-e16. [CrossRef]

11. Ruwende, C.; Khoo, S.C.; Snow, R.W.; Yates, S.N.; Kwiatkowski, D.; Gupta, S.; Warn, P.; Allsopp, C.E.; Gilbert, S.C.; Peschu, N.; et al. Natural selection of hemi- and heterozygotes for G6PD deficiency in Africa by resistance to severe malaria. Nature 1995, 376, 246-249. [CrossRef] [PubMed]

12. Preuss, J.; Jortzik, E.; Becker, K. Glucose-6-phosphate metabolism in Plasmodium falciparum. IUBMB Life 2012, 64, 603-611. [CrossRef] [PubMed]

13. Wakao, S.; Benning, C. Genome-wide analysis of glucose-6-phosphate dehydrogenases in Arabidopsis. Plant J. 2005, 41, 243-256. [CrossRef] [PubMed]

14. Meyer, T.; Hölscher, C.; Schwöppe, C.; von Schaewen, A. Alternative targeting of Arabidopsis plastidic glucose-6-phosphate dehydrogenase G6PD1 involves cysteine-dependent interaction with G6PD4 in the cytosol. Plant J. 2011, 66, 745-758. [CrossRef]

15. Graeve, K.; von Schaewen, A.; Scheibe, R. Purification, characterization, and cDNA sequence of glucose-6-phosphate dehydrogenase from potato (Solanum tuberosum L). Plant J. 1994, 5, 353-361. [CrossRef]

16. Neé, G.; Aumont-Nicaise, M.; Zaffagnini, M.; Nessler, S.; Valerio-Lepiniec, M.; Issakidis-Bourguet, E. Redox regulation of chloroplastic G6PDH activity by thioredoxin occurs through structural changes modifying substrate accessibility and cofactor binding. Biochem. J. 2014, 457. [CrossRef]

17. Wenderoth, I.; Scheibe, R.; von Schaewen, A. Identification of the cysteine residues involved in redox modification of plant plastidic glucose-6-phosphate dehydrogenase. J. Biol. Chem. 1997, 272, 26985-26990. [CrossRef]

18. Scheibe, R.; Geissler, A.; Fickenscher, K. Chloroplast glucose-6-phosphate dehydrogenase: Km shift upon light modulation and reduction. Arch. Biochem. Biophys. 1989, 274, 290-297. [CrossRef]

19. Knüsting, J.; Scheibe, R. Small molecules govern thiol redox switches. Trends Plant. Sci. 2018, 23, 769-782. [CrossRef]

20. Von Schaewen, A.; Langenkamper, G.; Graeve, K.; Wenderoth, I.; Scheibe, R. Molecular characterization of the plastidic glucose-6-phosphate dehydrogenase from potato in comparison to its cytosolic counterpart. Plant Physiol. 1995, 109, 1327-1335. [CrossRef]

21. Cardi, M.; Zaffagnini, M.; De Lillo, A.; Castiglia, D.; Chibani, K.; Gualberto, J.M.; Rouhier, N.; Jacquot, J.P.; Esposito, S. Plastidic P2 glucose-6P dehydrogenase from poplar is modulated by thioredoxin m-type: Distinct roles of cysteine residues in redox regulation and NADPH inhibition. Plant Sci. 2016, 252, 257-266. [CrossRef] [PubMed]

22. Landi, S.; Nurcato, R.; De Lillo, A.; Lentini, M.; Grillo, S.; Esposito, S. Glucose-6-phosphate dehydrogenase plays a central role in the response of tomato (Solanum lycopersicum) plants to short and long-term drought. Plant Physiol. Biochem. 2016, 105, 79-89. [CrossRef]

23. Wang, X.; Ma, Y.; Huang, C.; Li, J.; Wan, Q.; Bi, Y. Involvement of glucose-6-phosphate dehydrogenase in reduced glutathione maintenance and hydrogen peroxide signal under salt stress. Plant Signal Behav. 2008, 3, 394-395. [CrossRef] [PubMed]

24. Yang, Y.; Fu, Z.; Su, Y.; Zhang, X.; Li, G.; Guo, J.; Que, Y.; Xu, L. A cytosolic glucose-6-phosphate dehydrogenase gene, ScG6PDH, plays a positive role in response to various abiotic stresses in sugarcane. Sci. Rep. 2014, 4, 7090. [CrossRef] [PubMed]

25. Debnam, P.M.; Fernie, A.R.; Leisse, A.; Golding, A.; Bowsher, C.G.; Grimshaw, C.; Knight, J.S.; Emes, M.J. Altered activity of the P2 isoform of plastidic glucose 6-phosphate dehydrogenase in tobacco (Nicotiana tabacum cv. Samsun) causes changes in carbohydrate metabolism and response to oxidative stress in leaves. Plant J. 2004, 38, 49-59. [CrossRef] 
26. Scharte, J.; Schon, H.; Tjaden, Z.; Weis, E.; von Schaewen, A. Isoenzyme replacement of glucose-6-phosphate dehydrogenase in the cytosol improves stress tolerance in plants. Proc. Natl. Acad. Sci. USA 2009, 106, 8061-8066. [CrossRef]

27. Bussell, J.D.; Keech, O.; Fenske, R.; Smith, S.M. Requirement for the plastidial oxidative pentose phosphate pathway for nitrate assimilation in Arabidopsis. Plant J. 2013, 75, 578-591. [CrossRef]

28. Esposito, S. Nitrogen assimilation, abiotic stress and glucose 6-phosphate dehydrogenase: The full circle of reductants. Plants 2016, 5. [CrossRef]

29. Lobo, Z.; Maitra, P.K. Pentose phosphate pathway mutants of yeast. Mol. Gen. Genet. 1982, 185, $367-368$. [CrossRef]

30. Nogae, I.; Johnston, M. Isolation and characterization of the ZWF1 gene of Saccharomyces cerevisiae, encoding glucose-6-phosphate dehydrogenase. Gene 1990, 96, 161-169. [CrossRef]

31. Thomas, D.; Cherest, H.; Surdin-Kerjan, Y. Identification of the structural gene for glucose-6-phosphate dehydrogenase in yeast. Inactivation leads to a nutritional requirement for organic sulfur. EMBO J. 1991, 10, 547-553. [CrossRef] [PubMed]

32. Krüger, A.; Gruning, N.M.; Wamelink, M.M.; Kerick, M.; Kirpy, A.; Parkhomchuk, D.; Bluemlein, K.; Schweiger, M.R.; Soldatov, A.; Lehrach, H.; et al. The pentose phosphate pathway is a metabolic redox sensor and regulates transcription during the antioxidant response. Antioxid. Redox. Signal 2011, 15, 311-324. [CrossRef] [PubMed]

33. Stincone, A.; Prigione, A.; Cramer, T.; Wamelink, M.M.; Campbell, K.; Cheung, E.; Olin-Sandoval, V.; Gruning, N.M.; Kruger, A.; Tauqeer Alam, M.; et al. The return of metabolism: Biochemistry and physiology of the pentose phosphate pathway. Biol. Rev. Camb. Philos. Soc. 2015, 90, 927-963. [CrossRef] [PubMed]

34. Lagunas, R.; Gancedo, J.M. Reduced pyridine-nucleotides balance in glucose-growing Saccharomyces cerevisiae. Eur. J. Biochem. 1973, 37, 90-94. [CrossRef]

35. Jacoby, J.; Hollenberg, C.P.; Heinisch, J.J. Transaldolase mutants in the yeast Kluyveromyces lactis provide evidence that glucose can be metabolized through the pentose phosphate pathway. Mol. Microbiol. 1993, 10, 867-876. [CrossRef]

36. Rodicio, R.; Heinisch, J.J. Yeast on the milky way: Genetics, physiology and biotechnology of Kluyveromyces lactis. Yeast 2013, 30, 165-177. [CrossRef]

37. Ralser, M.; Wamelink, M.M.; Kowald, A.; Gerisch, B.; Heeren, G.; Struys, E.A.; Klipp, E.; Jakobs, C.; Breitenbach, M.; Lehrach, H.; et al. Dynamic rerouting of the carbohydrate flux is key to counteracting oxidative stress. J. Biol. 2007, 6. [CrossRef]

38. Dick, T.P.; Ralser, M. Metabolic Remodeling in Times of Stress: Who Shoots Faster than His Shadow? Mol. Cell 2015, 59, 519-521. [CrossRef]

39. Kuehne, A.; Emmert, H.; Soehle, J.; Winnefeld, M.; Fischer, F.; Wenck, H.; Gallinat, S.; Terstegen, L.; Lucius, R.; Hildebrand, J.; et al. Acute activation of oxidative pentose phosphate pathway as first-line response to oxidative stress in human skin cells. Mol. Cell 2015, 59, 359-371. [CrossRef]

40. Yoshida, A.; Lin, M. Regulation of glucose-6-phosphate dehydrogenase activity in red blood cells from hemolytic and nonhemolytic variant subjects. Blood 1973, 41, 877-891. [CrossRef]

41. Hildebrandt, T.; Knuesting, J.; Berndt, C.; Morgan, B.; Scheibe, R. Cytosolic thiol switches regulating basic cellular functions: GAPDH as an information hub? Biol. Chem. 2015, 396, 523-537. [CrossRef] [PubMed]

42. Peralta, D.; Bronowska, A.K.; Morgan, B.; Doka, E.; Van Laer, K.; Nagy, P.; Grater, F.; Dick, T.P. A proton relay enhances $\mathrm{H}_{2} \mathrm{O}_{2}$ sensitivity of GAPDH to facilitate metabolic adaptation. Nat. Chem. Biol. 2015, 11, 156-163. [CrossRef] [PubMed]

43. Arvanitidis, A.; Heinisch, J.J. Studies on the function of yeast phosphofructokinase subunits by in vitro mutagenesis. J. Biol. Chem. 1994, 269, 8911-8918. [PubMed]

44. Kirchrath, L.; Lorberg, A.; Schmitz, H.P.; Gengenbacher, U.; Heinisch, J.J. Comparative genetic and physiological studies of the MAP kinase Mpk1p from Kluyveromyces lactis and Saccharomyces cerevisiae. J. Mol. Biol. 2000, 300, 743-758. [CrossRef]

45. Schacherer, J.; Ruderfer, D.M.; Gresham, D.; Dolinski, K.; Botstein, D.; Kruglyak, L. Genome-wide analysis of nucleotide-level variation in commonly used Saccharomyces cerevisiae strains. PLoS ONE 2007, 2, e322. [CrossRef]

46. Rose, M.D.; Winston, F.; Hieter, P. Methods in Yeast Genetics; Cold Harbor Spring Laboratory: New York, NY, USA, 1990. 
47. Schmitz, H.P.; Jendretzki, A.; Wittland, J.; Wiechert, J.; Heinisch, J.J. Identification of Dck1 and Lmo1 as upstream regulators of the small GTPase Rho5 in Saccharomyces cerevisiae. Mol. Microbiol. 2015, 96, 306-324. [CrossRef]

48. Rothstein, R. Targeting, disruption, replacement, and allele rescue: Integrative DNA transformation in yeast. Methods Enzymol. 1991, 194, 281-301.

49. Brachmann, C.B.; Davies, A.; Cost, G.J.; Caputo, E.; Li, J.; Hieter, P.; Boeke, J.D. Designer deletion strains derived from Saccharomyces cerevisiae S288C: A useful set of strains and plasmids for PCR-mediated gene disruption and other applications. Yeast 1998, 14, 115-132. [CrossRef]

50. Sherman, F.; Fink, G.R.; Hicks, J.B. Laboratory Course Manual for Methods in Yeast Genetics; Cold Spring Harbour Laboratory: New York, NY, USA, 1986.

51. Schneider, M.; Knuesting, J.; Birkholz, O.; Heinisch, J.J.; Scheibe, R. Cytosolic GAPDH as a redox-dependent regulator of energy metabolism. BMC Plant Biol. 2018, 18, 184. [CrossRef]

52. Longtine, M.S.; McKenzie, A., 3rd; Demarini, D.J.; Shah, N.G.; Wach, A.; Brachat, A.; Philippsen, P.; Pringle, J.R. Additional modules for versatile and economical PCR-based gene deletion and modification in Saccharomyces cerevisiae. Yeast 1998, 14, 953-961. [CrossRef]

53. Rodicio, R.; Koch, S.; Schmitz, H.P.; Heinisch, J.J. KlRHO1 and KlPKC1 are essential for cell integrity signalling in Kluyveromyces lactis. Microbiology 2006, 152, 2635-2649. [CrossRef] [PubMed]

54. Kock, C.; Arlt, H.; Ungermann, C.; Heinisch, J.J. Yeast cell wall integrity sensors form specific plasma membrane microdomains important for signalling. Cell Microbiol. 2016, 18, 1251-1267. [CrossRef] [PubMed]

55. Heinisch, J. Construction and physiological characterization of mutants disrupted in the phosphofructokinase genes of Saccharomyces cerevisiae. Curr. Genet. 1986, 11, 227-234. [CrossRef]

56. Schaaff-Gerstenschlager, I.; Zimmermann, F.K. Pentose-phosphate pathway in Saccharomyces cerevisiae: Analysis of deletion mutants for transketolase, transaldolase, and glucose 6-phosphate dehydrogenase. Curr. Genet. 1993, 24, 373-376. [CrossRef]

57. Dowell, R.D.; Ryan, O.; Jansen, A.; Cheung, D.; Agarwala, S.; Danford, T.; Bernstein, D.A.; Rolfe, P.A.; Heisler, L.E.; Chin, B.; et al. Genotype to phenotype: A complex problem. Science 2010, 328, 469. [CrossRef]

58. Miosga, T.; Zimmermann, F.K. Cloning and characterization of the first two genes of the non-oxidative part of the Saccharomyces cerevisiae pentose-phosphate pathway. Curr. Genet. 1996, 30, 404-409. [CrossRef]

59. Zimmermann, A.; Hofer, S.; Pendl, T.; Kainz, K.; Madeo, F.; Carmona-Gutierrez, D. Yeast as a tool to identify anti-aging compounds. FEMS Yeast Res. 2018, 18. [CrossRef]

60. Levy, H.R.; Vought, V.E.; Yin, X.; Adams, M.J. Identification of an arginine residue in the dual coenzyme-specific glucose-6-phosphate dehydrogenase from Leuconostoc mesenteroides that plays a key role in binding NADP ${ }^{+}$ but not NAD ${ }^{+}$. Arch. Biochem. Biophys. 1996, 326, 145-151. [CrossRef]

61. Vought, V.; Ciccone, T.; Davino, M.H.; Fairbairn, L.; Lin, Y.; Cosgrove, M.S.; Adams, M.J.; Levy, H.R. Delineation of the roles of amino acids involved in the catalytic functions of Leuconostoc mesenteroides glucose 6-phosphate dehydrogenase. Biochemistry 2000, 39, 15012-15021. [CrossRef]

62. Nissen, T.L.; Anderlund, M.; Nielsen, J.; Villadsen, J.; Kielland-Brandt, M.C. Expression of a cytoplasmic transhydrogenase in Saccharomyces cerevisiae results in formation of 2-oxoglutarate due to depletion of the NADPH pool. Yeast 2001, 18, 19-32. [CrossRef]

63. Jeppsson, M.; Johansson, B.; Hahn-Hagerdal, B.; Gorwa-Grauslund, M.F. Reduced oxidative pentose phosphate pathway flux in recombinant xylose-utilizing Saccharomyces cerevisiae strains improves the ethanol yield from xylose. Appl. Environ. Microbiol. 2002, 68, 1604-1609. [CrossRef] [PubMed]

64. Gorsich, S.W.; Dien, B.S.; Nichols, N.N.; Slininger, P.J.; Liu, Z.L.; Skory, C.D. Tolerance to furfural-induced stress is associated with pentose phosphate pathway genes ZWF1, GND1, RPE1, and TKL1 in Saccharomyces cerevisiae. Appl. Microbiol. Biotechnol. 2006, 71, 339-349. [CrossRef] [PubMed]

65. Fletcher, E.; Gao, K.; Mercurio, K.; Ali, M.; Baetz, K. Yeast chemogenomic screen identifies distinct metabolic pathways required to tolerate exposure to phenolic fermentation inhibitors ferulic acid, 4-hydroxybenzoic acid and coniferyl aldehyde. Metab. Eng. 2019, 52, 98-109. [CrossRef] [PubMed]

66. Kwak, S.; Yun, E.J.; Lane, S.; Oh, E.J.; Kim, K.H.; Jin, Y.S. Redirection of the glycolytic flux enhances isoprenoid production in Saccharomyces cerevisiae. Biotechnol. J. 2020, 15, e1900173. [CrossRef] 
67. Zhao, X.; Shi, F.; Zhan, W. Overexpression of ZWF1 and POS5 improves carotenoid biosynthesis in recombinant Saccharomyces cerevisiae. Lett. Appl. Microbiol. 2015, 61, 354-360. [CrossRef]

68. Cardenas, J.; Da Silva, N.A. Engineering cofactor and transport mechanisms in Saccharomyces cerevisiae for enhanced acetyl-CoA and polyketide biosynthesis. Metab. Eng. 2016, 36, 80-89. [CrossRef]

(C) 2020 by the authors. Licensee MDPI, Basel, Switzerland. This article is an open access article distributed under the terms and conditions of the Creative Commons Attribution (CC BY) license (http://creativecommons.org/licenses/by/4.0/). 